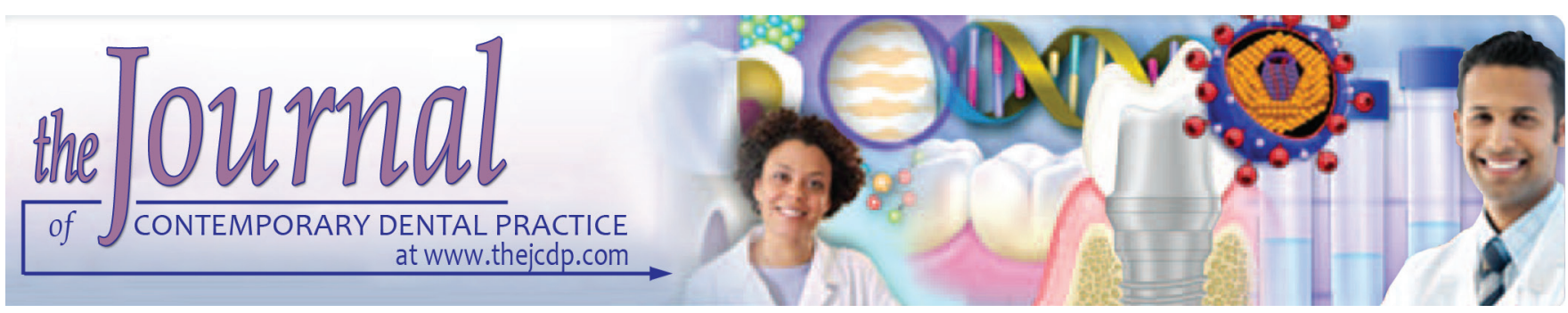

\title{
Effect of Topical Honey on Mandibular Bone Defect Healing in Rats
}

\author{
${ }^{1}$ Farhad Hajizadeh, ${ }^{2}$ Bahman Derakhshan, ${ }^{3}$ Ali Peimani, ${ }^{4}$ Zahra Abbasi
}

\begin{abstract}
Aim: In medicine, honey is known for its various biological or pharmacological effects, from wound dressing to anticancerogenic and from anti-inflammatory to antibacterial activities. The aim of the current study was to evaluate the effect of honey on healing of mandibular bone defects in a rat model.

Materials and methods: This animal study was performed on 24 wild-type Wistar rats. Following shaving, disinfection, and extraoral incision, a $2 \times 2 \mathrm{~mm}$ defect was created at mandibular angle. In the experimental group, the defect was filled with sterile honey, while it was left unfilled in the control group. The rats were sacrificed after 2 and 4 weeks and defects were assessed histologically. The results were compared using Mann-Whitney U-test $(\alpha=0.05)$.
\end{abstract}

Results: After 2 weeks, five samples of the experimental group were in mineralization phase, while all samples of the control group were in the vascularization phase $(p=0.015)$. After 4 weeks, the defects were filled in four samples of the experimental group, while all samples of the control group were in the mineralization stage $(p=0.002)$. Histomorphometric assessment revealed that the mean new bone formation in the experimental group was significantly more than the control group, both after 2 and 4 weeks $(p=0.041)$.

\footnotetext{
${ }^{1}$ Department of Periodontics, School of Dentistry, Shahid Beheshti University of Medical Sciences, Tehran, Islamic Republic of Iran

${ }^{2}$ Department of Oral and Maxillofacial Surgery, International Campus School of Dentistry, Tehran University of Medical Sciences, Tehran, Islamic Republic of Iran

${ }^{3}$ Department of Oral and Maxillofacial Surgery, Rafsanjan University of Medical Sciences, Rafsanjan, Islamic Republic of Iran

${ }^{4}$ Department of Otolaryngology-Head and Neck Surgery Hamedan University of Medical Sciences, Hamedan, Islamic Republic of Iran

Corresponding Author: Zahra Abbasi, Department of Otolaryngology-Head and Neck Surgery, Hamedan University of Medical Sciences, Hamedan, Islamic Republic of Iran, Phone: +989125176083, e-mail: abbasizahra@yahoo.com
}

Conclusion: The results showed that honey could accentuate bone healing of mandibular small defects in rats.

Clinical significance: Honey might have potential in repair of human alveolar bone defects.

Keywords: Bone regeneration, Honey, Mandible.

How to cite this article: Hajizadeh F, Derakhshan B, Peimani A, Abbasi Z. Effect of Topical Honey on Mandibular Bone Defect Healing in Rats. J Contemp Dent Pract 2018;19(1):47-51.

\section{Source of support: Nil}

\section{Conflict of Interest: None}

\section{INTRODUCTION}

Regeneration and repair of bone defects due to congenital diseases, such as alveolar defects, pathologic conditions, trauma, and gunshot injury need surgical intervention. ${ }^{1}$ More than 1 million bone regeneration surgeries are performed each year worldwide. The gold standard modality for treatment of critical-sized bone defects is autogenous bone graft. ${ }^{2,3}$ However, due to its limitations, other techniques, such as stem cell therapy and alloplastic grafts have been developed. ${ }^{4-7}$

Repair of bone defects comprises three major stages: Inflammation, repair, and remodeling. 8,9 During the inflammatory stage, leukocytes and fibroblasts infiltrate bone defect under regulation of cytokines, followed by angiogenesis. Then, fibroblasts produce a collagen matrix, osteoids are secreted and mineralized. The remodeling stage completes bone repair. ${ }^{10}$ Although small and noncritical sized bone defects do not necessitate bone grafts, their repair could be accelerated by intervention. ${ }^{11-13}$

Honey is one of the oldest food resources for humans. In addition, it is known for its curing effect in the treatment of various medical diseases. ${ }^{14-16}$ Early in the 20th century, its wound-healing feature was demonstrated; however, it was overlooked due to the introduction of antibiotics. ${ }^{10-12}$ Honey contains about 200 substances 
that could influence the physiology of tissue repair. ${ }^{17}$ The antibacterial and anti-inflammatory effects of honey have been reported in several studies. ${ }^{18-23}$ In addition, honey contains vitamin $\mathrm{C}$ concentration three times more than plasma, ${ }^{24}$ which could accelerate tissue regeneration. ${ }^{25} \mathrm{~A}$ recent clinical trial showed the effectiveness of honey as a dressing for dry socket. ${ }^{26}$ Oral consumption of honey could improve bone structure in osteoporotic rats. ${ }^{27,28}$

In a recent review, it was demonstrated that honey could prevent cancerogenesis through alteration of cell cycle molecular processes ${ }^{19}$ and some studies reviewed the effectiveness of honey for wound healing. ${ }^{18,29,30}$ Although several studies demonstrated the soft tissue wound healing effect of honey, ${ }^{18,23,29,30}$ its effect on bone defects has not been evaluated. Hence, the aim of the current study was to evaluate the effect of honey on healing of mandibular bone defects in a rat model.

\section{MATERIALS AND METHODS}

\section{Study Design}

This animal study was performed on 24 seven-week-old wild-type Wistar male rats that weighted approximately 450 gm (420-470 gm). The study protocol was approved by Institutional Animal Care and Use Committee of the Shahid Beheshti University of Medical Sciences. All animals were kept in a monitored environment and separate cages. They had access to sufficient drinking water and laboratory rat food. All the animals were generally healthy before and throughout the experiment according to veterinarian examinations.

\section{Surgical Procedure}

Animals were anesthetized using ketamine hydrochloride (5 mg/kg; Iran Daru Pharmaceutical Co., Tehran, Iran) and xylazine ( $3 \mathrm{mg} / \mathrm{kg}$; Iran Daru Pharmaceutical Co.). These drugs were injected intraperitoneally using insulin syringe. Mandibular angle and border of the right side were shaved and disinfected with povidone-iodine (Betadine). An extraoral incision was made by a sharp blade at the mandibular border and a full-thickness flap was reflected to expose mandibular angle. A $2 \times 2 \mathrm{~mm}$ diameter unicortical bone defect was created using surgical bur (Meisinger, Neuss, Germany) with the speed of 20,000 (rev/min) under sufficient irrigation of normal saline in a sterilized condition.

The animals were randomly divided into two groups. In group I (experimental group, $\mathrm{n}=12$ ), the defect was filled with one drop of sterile honey (Medihoney, Derma Sciences Inc., Princeton, New Jersey) and in group II (control group, $\mathrm{n}=12$ ), the defect was left unfilled. No membrane was used to cover the defects. The incision was closed using 3-0 Vicryl (Ethicon Inc., Somerville,
New Jersey) suture. Analgesic ( $0.1 \mathrm{~mL} / \mathrm{kg}$ of ketoprofen) and antibiotics $(20 \mathrm{mg} / \mathrm{kg}$ of oxytetracycline) were administered both preoperatively and postoperatively.

\section{Assessment of Healing}

At 2 and 4 weeks after the surgery, animals were sacrificed humanely. Mandible was dissected, dehydrated, and mounted in methyl methacrylate resin. The samples were fixed in $10 \%$ formalin solution with a $\mathrm{pH}$ of 7 . Following the fixation in formalin for 1 week, the samples were moved to $4 \%$ ethylenediaminetetraacetate solution for 4 weeks to decalcify hard tissue. Then, the samples were processed using tissue processor machine (DidehSabz Company, Tehran, Iran). After 24 hours, samples were prepared with paraffin infiltration, and sequential sections $(5 \mu \mathrm{m})$ were cut perpendicular to the defect. The sections were stained with hematoxylin and eosin. Three slices of each sample that represented the most central cuts were selected and assessed histologically for evaluation of the healing stage. The samples were assessed by an experienced pathologist and graded according to their stage of bone repair (grade I: Inflammatory cells and blood clot; grade II: Vascularization and sequestration; grade III: Osteoid, mineralization, and cortical bone; and grade IV: Defect filled with new bone). ${ }^{10}$ In addition, the number of lymphocytes and neutrophils as well as blood vessels was counted in five randomly selected different fields of each slice $(\times 1000$ for cells and $\times 400$ for vessels), and its mean number was accounted for that specimen.

The most central slice was selected (largest diameter) and digitized with microscope digital camera and analyzed by an image-analyzing computer software (ImagePro Plus, Media Cybernetic, Silver Spring, MD). The area of bone tissue in the defect was expressed as percentage.

\section{Statistical Analysis}

Comparison of the healing grades of two groups as well as their histomorphometric results was performed by MannWhitney U-test. All statistical analyses were performed by Statistical Package for the Social Sciences software (SPSS Inc., Chicago, Illinois) with a significance level of 0.05 .

\section{RESULTS}

After 2 weeks, five samples of the experimental group were of grade III (mineralization) and one sample was of grade II, while all samples of the control group were of grade II (vascularization) ( $p=0.015)$. After 4 weeks, the defects were nearly filled in all samples. At this time, four samples of the experimental group were of grade IV (defect was filled with new bone) and two samples were of grade III, while all samples of the control group were of grade III (mineralization; $\mathrm{p}=0.002$; Fig. 1). 

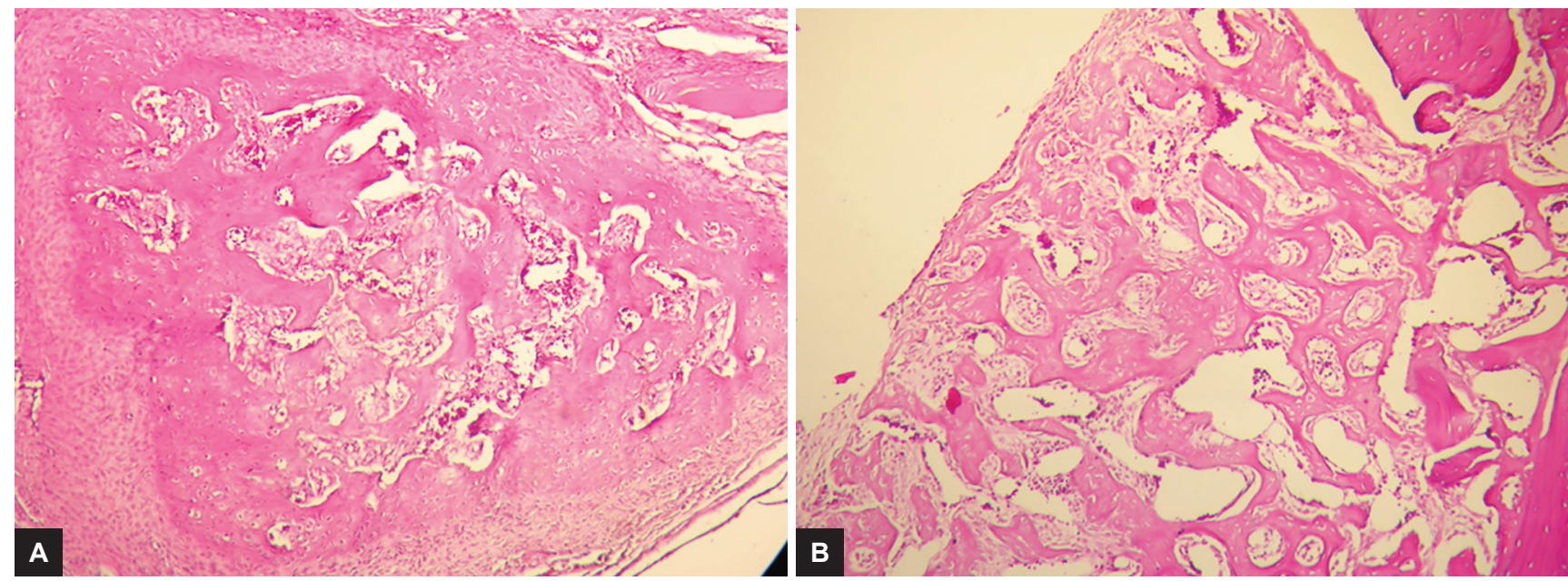

Figs 1A and B: Histologic evaluation of mandibular bone defects after 4 weeks in: (A) Control group; and (B) experimental group

Table 1: Comparison of wound healing between two groups

\begin{tabular}{|c|c|c|c|c|c|c|}
\hline \multirow[b]{2}{*}{ Index } & \multirow[b]{2}{*}{ Time } & \multicolumn{2}{|c|}{ Experimental group } & \multicolumn{2}{|c|}{ Control group } & \multirow[b]{2}{*}{$p$-value } \\
\hline & & Count & Mean $\pm S D$ & Count & Mean $\pm S D$ & \\
\hline \multirow[t]{2}{*}{ Lymphocytes* } & 2nd week & 6 & $17.83 \pm 5.00$ & 6 & $17.17 \pm 4.12$ & 0.818 \\
\hline & 4th week & 6 & $4.50 \pm 2.07$ & 6 & $4.00 \pm 1.41$ & 0.818 \\
\hline \multirow[t]{2}{*}{ Neutrophils* } & 2nd week & 6 & $10.33 \pm 3.08$ & 6 & $11.17 \pm 2.93$ & 0.699 \\
\hline & 4th week & 6 & $1.83 \pm 1.17$ & 6 & $1.50 \pm 1.22$ & 0.818 \\
\hline \multirow[t]{2}{*}{ Blood vessels** } & 2nd week & 6 & $11.50 \pm 1.87$ & 6 & $7.50 \pm 2.35$ & 0.009 \\
\hline & 4th week & 6 & $7.83 \pm 1.94$ & 6 & $4.00 \pm 1.67$ & 0.015 \\
\hline
\end{tabular}

*Mean number of cells at $\times 1000 ;{ }^{* *}$ mean number of vessels at $\times 400$

The results of inflammatory cells and blood vessels counting are demonstrated in Table 1. The number of cells was not statistically different between two groups; however, statistically significant lesser blood vessels were observed in the experimental group, both after 14 and 28 days $(\mathrm{p}<0.05)$.

The mean (standard deviation, SD) new bone formation in the experimental group was $36.83 \%$ (9.33) and $64.33 \%$ (10.69) after 2 and 4 weeks respectively. The corresponding numbers for the control group were 27.00 (6.72) and 52.33 (7.45) respectively. As demonstrated in Graph 1,

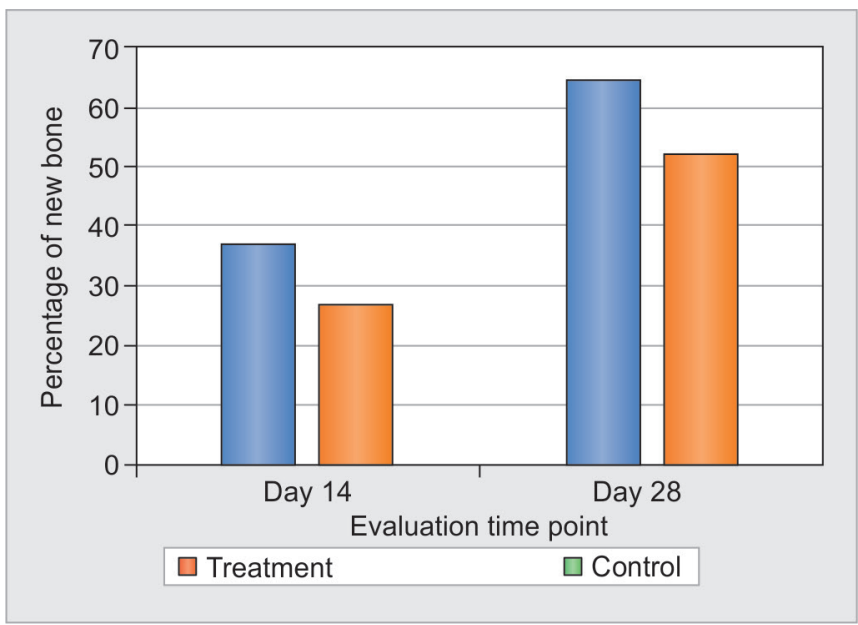

Graph 1: Mean new bone formation according to histomorphometric analysis [the difference between two groups was significant at both time points $(p=0.041)]$ the difference in mean new bone formation between two groups was statistically significant, both after 2 and 4 weeks $(p=0.041)$.

\section{DISCUSSION}

This study was performed to assess bone reparative potential of honey, and the results demonstrated its significant influence on repair of small-sized mandibular defect in a rat model. To the extent of our knowledge, this was the first report on the effect of honey on bone repair. The regeneration acceleration property of the honey could be attributed to its anti-inflammatory, antibacterial, and angiogenesis effects.

Some authors have investigated the effect of honey on the inflammation. A study showed that honey flavonoid extract significantly suppressed the secretion of proinflammatory cytokines including tumor necrosis factoralpha (TNF- $\alpha$ ) and interleukin (IL)- 1 beta. ${ }^{20}$ In an in vivo study on rats, Hussein et $\mathrm{al}^{21}$ showed that honey could decrease edema and also decrease the levels of inflammatory mediators including prostaglandin E2, TNF- $\alpha$, nitric oxide, and IL-6 in the plasma. Its anti-inflammatory effect was similar to that of indomethacin. It has been revealed that the anti-inflammatory property of the honey could be due to its phenolic and flavonoids compounds. . $^{27,31}$

Several studies have reported the antibacterial effect of honey, ${ }^{22,23}$ which results in inhibition of bacterial 
colonization and promotes wound healing. ${ }^{32}$ Antibacterial effect of honey is attributed to the riboflavin. ${ }^{32}$ In addition, honey contains enzymes, such as catalase, which could have an antibacterial effect. ${ }^{33}$ The $\mathrm{pH}$ of honey is low enough (3.2-4.5) to prevent bacterial growth. ${ }^{26}$

A significant stage of bone repair is vascularization for providing enough oxygen and nutrition for the cells involved in healing process. Previously, some studies reported that honey could accelerate wound healing by granulation tissue formation. ${ }^{22,34}$ Vascularization was significantly more in skin lesions dressed with honey compared with the control group. ${ }^{34}$ The bacteria present in the lesion could consume glucose of honey and produce lactic acid, which could play a role in angiogenesis. ${ }^{35}$ In addition, honey contains hydrogen peroxide, which has insulin-like effects and could cause growth of the cells. ${ }^{36}$

Honey contains several vitamins and other nutritional components, which could positively influence wound healing. ${ }^{32}$ Honey has high concentrations of vitamin $C^{24}$ This might accelerate collagen synthesis by fibroblasts resulting in hastening of bone healing.

Regarding the safety of application of honey in the bone defects, sterilization seems necessary. The presence of clostridial spores in honey could cause food poisoning in children. ${ }^{37,38}$ However, Molan ${ }^{39}$ reported that application of unsterile honey on open wounds of 470 patients caused no infection.

Although translation of this limited animal study to the clinical situation is not appropriate, the results indicated the potential of honey in bone healing. Furthermore, the molecular process of bone healing through honey was not assessed in this preliminary animal study. More in vivo studies should be performed to evaluate the effectiveness of honey in repair of bone lesions, such as periodontal defects.

\section{CONCLUSION}

Within the limitations of this animal study, the results demonstrated that honey could increase and accelerate bone repair of mandibular small defects in rats. These results indicate the possible potential of honey for application in bone regeneration and repair.

\section{Clinical Significance}

The results showed that medical honey could accelerate healing of mandibular bone noncritical-sized defect.

\section{REFERENCES}

1. Motamedian SR, Iranparvar P, Nahvi G, Khojasteh A. Bone tissue engineering: a literature review. Regen Reconstr Restor 2016 Apr;1(3):103-120.
2. Motamedian SR, Khojaste M, Khojasteh A. Success rate of implants placed in autogenous bone blocks versus allogenic bone blocks: a systematic literature review. Ann Maxillofac Surg 2016 Jan-Jun;6(1):78-90.

3. Khojasteh A, Kheiri L, Motamedian SR, Nadjmi N. Regenerative medicine in the treatment of alveolar cleft defect: a systematic review of the literature. J Craniomaxillofac Surg 2015 Oct;43(8):1608-1613.

4. HosseinpourS,GhazziadehAhsaieM,Rezai RadM,BaghaniMT, Motamedian SR, Khojasteh A. Application of selected scaffolds for bone tissue engineering: a systematic review. Oral Maxillofac Surg 2017 Jun;21(2):109-129.

5. Motamedian SR, Hosseinpour S, Ahsaie MG, Khojasteh A. Smart scaffolds in bone tissue engineering: a systematic review of literature. World J Stem Cells 2015 Apr;7(3):657-668.

6. Motamedian SR, Tabatabaei FS, Akhlaghi F, Torshabi M, Gholamin P, Khojasteh A. Response of dental pulp stem cells to synthetic, allograft, and xenograft bone scaffolds. Int J Periodontics Restorative Dent 2016 Aug.

7. KhojastehA,MotamedianSR,RadMR,ShahriariMH,NadjmiN. Polymeric vs hydroxyapatite-based scaffolds on dental pulp stem cell proliferation and differentiation. World J Stem Cells 2015 Nov;7(10):1215-1221.

8. DePalma AF, Rothman RH, Lewinnek GE, Canale ST. Anterior interbody fusion for severe cervical disc degeneration. Surg Gynecol Obstet 1972 May;134(5):755-758.

9. Burchardt H, Enneking WF. Transplantation of bone. Surg Clin North Am 1978 Apr;58(2):403-427.

10. Kalfas IH. Principles of bone healing. Neurosurg Focus 2001 Apr;10(4):E1.

11. Melo LG, Nagata MJ, Bosco AF, Ribeiro LL, Leite CM. Bone healing in surgically created defects treated with either bioactive glass particles, a calcium sulfate barrier, or a combination of both materials. A histological and histometric study in rat tibias. Clin Oral Implants Res 2005 Dec;16(6):683-691.

12. Pautke C, Vogt S, Tischer T, Wexel G, Deppe H, Milz S, Schieker M, Kolk A. Polychrome labeling of bone with seven different fluorochromes: enhancing fluorochrome discrimination by spectral image analysis. Bone 2005 Oct;37(4):441-445.

13. Schneider OD, Weber F, Brunner TJ, Loher S, Ehrbar M, Schmidlin PR, Stark WJ. In vivo and in vitro evaluation of flexible, cottonwool-like nanocomposites as bone substitute material for complex defects. Acta Biomater 2009 Jun;5(5):1775-1784.

14. Al-Waili NS. Effects of daily consumption of honey solution on hematological indices and blood levels of minerals and enzymes in normal individuals. J Med Food 2003 Summer;6(2):135-140.

15. Al-Waili NS, Saloom KS, Al-Waili TN, Al-Waili AN. The safety and efficacy of a mixture of honey, olive oil, and beeswax for the management of hemorrhoids and anal fissure: a pilot study. Sci World J 2006 Feb;6:1998-2005.

16. Tavafzadeh SS, Ooi FK, Chen CK, Sulaiman SA, Hung LK. Bone mechanical properties and mineral density in response to cessation of jumping exercise and honey supplementation in young female rats. Biomed Res Int 2015 Jun;2015:938782.

17. Aljadi AM, Kamaruddin MY. Evaluation of the phenolic contents and antioxidant capacities of two Malaysian floral honeys. Food Chem 2004 May;85(4):513-518.

18. Vandamme L, Heyneman A, Hoeksema H, Verbelen J, Monstrey S. Honey in modern wound care: a systematic review. Burns 2013 Dec;39(8):1514-1525. 
19. Erejuwa OO, Sulaiman SA, Wahab MS. Effects of honey and its mechanisms of action on the development and progression of cancer. Molecules 2014 Feb;19(2):2497-2522.

20. CandiracciM,PiattiE,Dominguez-BarragánM,García-AntrásD, Morgado B, Ruano D, Gutiérrez JF, Parrado J, Castaño A. Anti-inflammatory activity of a honey flavonoid extract on lipopolysaccharide-activated N13 microglial cells. J Agric Food Chem 2012 Dec;60(50):12304-12311.

21. Hussein SZ, Yusoff KM, Makpol S, Mohd Yusof YA. Gelam honey inhibits the production of proinflammatory, mediators NO, PGE(2), TNF- $\alpha$, and IL-6 in carrageenan-induced acute paw edema in rats. Evid Based Complement Alternat Med 2012 Apr;2012:109636.

22. Molan PC. The antibacterial activity of honey. 1 . The nature of the antibacterial activity. Bee World 1992;73(1):5-28.

23. TanHT,RahmanRA, GanSH,HalimAS,HassanSA,SulaimanSA, Kirnpal-Kaur B. The antibacterial properties of Malaysian tualang honey against wound and enteric microorganisms in comparison to manuka honey. BMC Complement Altern Med 2009 Sep;9:34.

24. Schramm DD, Karim M, Schrader HR, Holt RR, Cardetti M, Keen CL. Honey with high levels of antioxidants can provide protection to healthy human subjects. J Agric Food Chem 2003 Mar;51(6):1732-1735.

25. Topham J. Why do some cavity wounds treated with honey or sugar paste heal without scarring? J Wound Care 2002 Feb;11(2):53-55.

26. Singh V, Pal US, Singh R, Soni N. Honey a sweet approach to alveolar osteitis: a study. Natl J Maxillofac Surg 2014 Jan;5(1):31-34.

27. Kassim M, Achoui M, Mustafa MR, Mohd MA, Yusoff KM. Ellagic acid, phenolic acids, and flavonoids in Malaysian honey extracts demonstrate in vitro anti-inflammatory activity. Nutr Res 2010 Sep;30(9):650-659.
28. Zaid SS, Sulaiman SA, Othman NH, Soelaiman IN, Shuid AN, Mohamad N, Muhamad N. Protective effects of tualang honey on bone structure in experimental postmenopausal rats. Clinics (Sao Paulo) 2012 Jul;67(7):779-784.

29. Wallace M. Review: evidence on the effectiveness of honey for healing wounds is limited. Evid Based Nurs 2009 Apr;12(2):53.

30. Lee DS, Sinno S, Khachemoune A. Honey and wound healing: an overview. Am J Clin Dermatol 2011 Jun;12(3):181-190.

31. Abubakar MB, Abdullah WZ, Sulaiman SA, Suen AB. A review of molecular mechanisms of the anti-leukemic effects of phenolic compounds in honey. Int J Mol Sci 2012 Nov;13(11):15054-15073.

32. Efem SE. Clinical observations on the wound healing properties of honey. Br J Surg 1988 Jul;75(7):679-681.

33. Weston RJ. The contribution of catalase and other natural products to the antibacterial activity of honey: a review. Food Chem 2000 Nov;71(2):235-239.

34. Sazegar G, Seyed Reza AH, Behravan E. The effects of supplemental zinc and honey on wound healing in rats. Iran J Basic Med Sci 2011 Jul;14(4):391-398.

35. Rendl M, Mayer C, Weninger W, Tschachler E. Topically applied lactic acid increases spontaneous secretion of vascular endothelial growth factor by human reconstructed epidermis. Br J Dermatol 2001 Jul;145(1):3-9.

36. May JM, de Haën C. The insulin-like effect of hydrogen peroxide on pathways of lipid synthesis in rat adipocytes. J Biol Chem 1979 Sep;254(18):9017-9021.

37. McMaster P, Piper S, Schell D, Gillis J, Chong A. A taste of honey. J Paediatr Child Health 2000 Dec;36(6):596-597.

38. Yanay O, Lerman-Sagie T, Gilad E, Nissenkorn A, Jaferi J, Watemberg N, Houri S. Infant botulism in Israel: knowledge enables prompt diagnosis. Isr Med Assoc J 2004 Apr;6(4):249-250.

39. Molan P. Why honey is effective as a medicine. 2. The scientific explanation of its effects. Bee World 2001;82(1):22-40. 